Research Article

\title{
Fracture Characteristics of Polyurethane Grouting Materials Based on Acoustic Emission Monitoring
}

\author{
Baihui Ren (D), ${ }^{1}$ Jianjun Shen $\left(\mathbb{D},{ }^{1,2}\right.$ Weitao Liu, ${ }^{3}$ Yingying $\mathrm{Hu}^{2}$ and Qing $\mathrm{Cao}^{2}$ \\ ${ }^{1}$ College of Safety and Environmental Engineering, Shandong University of Science and Technology, Qingdao 266590, China \\ ${ }^{2}$ College of Chemical Engineering and Safety, Binzhou Key Laboratory of Chemical Process Safety, Binzhou University, \\ Binzhou 256600, China \\ ${ }^{3}$ College of Energy and Mining Engineering, Shandong University of Science and Technology, Qingdao 266590, China
}

Correspondence should be addressed to Jianjun Shen; shenjianjun11987@163.com

Received 16 September 2020; Accepted 29 May 2021; Published 14 June 2021

Academic Editor: Carlo Rosso

Copyright (c) 2021 Baihui Ren et al. This is an open access article distributed under the Creative Commons Attribution License, which permits unrestricted use, distribution, and reproduction in any medium, provided the original work is properly cited.

\begin{abstract}
In this study, 16 groups of tests were designed by the orthogonal test method, and a PU grouting material was prepared, which can be used for the construction of sealing wall in mined-out area of coal mine. The basic properties of the material were measured. Firstly, the viscosity of four groups of samples with different polyether polyol contents was measured by a dynamic rheometer. Secondly, the uniaxial compressive strength of pure slurry samples and sand-containing samples was measured by a universal testing machine. Finally, the failure process of sand-containing samples was monitored by acoustic emission equipment. Through the above research and analysis, a PU grouting material with excellent performance has been obtained. That is, when the ratio of polyether triol:polyether tetraol:catalyst:surfactant:chain extender:plasticizer is $11: 9: 0.5: 1.0: 1.2: 6.0$, PU grouting material has higher injectability and ideal compressive strength, which has been proved in grouting experiments.
\end{abstract}

\section{Introduction}

The construction and development of coal mines continue to extend to the deep, and the hydrogeology and engineering geological conditions of mine mining are becoming more and more complex. Grouting technology, as an effective means of mine underground disaster control, has been widely used in coal mine safety production [1-3].

Previously, cement grouting materials were generally used for underground filling and reinforcement in coal mines. Although the reinforcement effect has been achieved, there are still weaknesses compared with chemical grout [4]. For example, the permeability is weak, the bonding performance is poor, and it is difficult to accurately adjust or control the set time, etc. [5]. PU grouting material is a kind of chemical grouting material that can quickly block water and prevent water leakage and can play a role in reinforcement. In recent years, more and more researchers have paid attention to it [6-8]. At present, there are many kinds of grouting materials in coal mines. Common filling and plugging materials include yellow mud grouting filling materials, fly ash filling materials, cement expansion filling materials, etc., but there are some limitations in the use process. Although these filling materials are widely used, the material preparation process is simple, and the filling cost is low, these filling materials can fix water and cool down in the early stage of filling to play a role in fire prevention, but they are easy to lose water and shrink in the later stage to form air leakage cracks, resulting in poor dynamic pressure resistance, resulting in unsatisfactory filling effect.

PU grouting material is a polymer compound generated by the reaction of isocyanate and polyether polyol. The product is carbamate, which is the repeating unit of polyurethane [9]. The synthesis of PU requires that the isocyanate and polyol group must contain not less than two isocyanate and hydroxy functional groups $[R-(N=C=$ $O) n \geq 2]$ and $[R-(O H) n \geq 2]$, respectively $[10,11]$. The properties of PU depend mainly on the type of isocyanate, polyol, and additives used in its synthesis process [12]. The additives commonly used in the synthesis of PU include 
catalysts [6], chain extenders [13, 14], fillers [15], blowing agents, surfactants [16, 17], flame retardants, and plasticizers [18], and each component plays an indispensable role.

In recent years, with the development and application of polymer grouting materials and the development of grouting material production technology, polymer grouting materials have been widely used in my country. Among them, PU grouting materials have been widely used in coal mines due to their unique advantages such as fast curing speed, high expansion ratio, and excellent flexibility. They are used in coal mining face to help control, fill large caving spaces, and quickly seal fissure water. Such safety fields have an irreplaceable role, which can provide effective support for the efficient and safe production of coal mines. In addition, some inorganic composite materials and modified materials are also under continuous research and development [19-24].

In the past studies, researchers paid more attention to the properties of PU grouting materials, including gel time, temperature, viscosity, foaming ratio, uniaxial compressive strength, permeability coefficient and grouting technology, etc. [25-29], and evaluate the quality of materials through a series of performance indexes [30]. For the measurement of viscosity, most people use viscometer, and the measured value is fixed, which has certain limitations. In addition, acoustic emission technology is mainly used for failure process and damage assessment of specimens under compression conditions [31, 32]. The parameters of acoustic emission waveform, such as energy, impact times, counting, amplitude, and frequency, are useful for identifying crack characteristics of concrete and masonry materials [33]. In the grouting experiment, the penetration and adhesion of polymer materials to soil are limited. Its infiltration results in the formation of a thin excessive cementation zone between the polymer and the soil. Due to the inhomogeneity and randomness of stress distribution, the splitting direction is uncertain [34]. Therefore, the grouting effect of materials should be determined according to the actual project.

The choice of grouting material is very important when grouting is used to treat the goaf of coal mine. Goaf grouting is different from common rock and soil grouting. The latter is often aimed at reinforcement and seepage prevention, while the former is aimed at filling goaf and its overlying rock and soil fissures. The reinforcement mechanism is mainly filling and compaction. In the construction of the airtight wall, the expansion effect of the PU grouting material can make the sealing wall and the surroundings of the roadway tightly integrated, avoiding the uneven surface of the roadway or the existence of filling corners, causing the filling to not completely fill the closed space, which is a good solution to problems with air ducts. The PU grouting material filling body prepared in this paper had low strength, good deformation, and certain bearing capacity and could be applied to the construction of sealing wall in goaf.

In this article, based on the requirements of plugging and strengthening the sealing wall in the mined-out area of coal mine, we prepared a two-component PU grouting material and measured the performance indexes such as viscosity, gel time, expansion ratio, compressive strength, etc. Because the basic performance index was not enough to completely evaluate the quality of materials, it would also be affected by other factors in actual engineering. Therefore, the grouting reinforcement test was carried out on the prepared grouting material, and the compressive strength of the sand-containing specimens was tested. At the same time, the parameters such as energy and counting when the samples break were measured by acoustic emission equipment. The innovation of this paper lies in the following: on the one hand, the shear stress and viscosity of slurry at different shear rates were measured by dynamic rheometer, and the linear fitting was carried out by Carreau model. On the other hand, acoustic emission technology was used to monitor the whole process of sand-containing specimens from initial crack generation to final failure. The material prepared in this paper has low viscosity and considerable strength and deformation. The airtight wall has a certain deformation ability, which can coordinate with the deformation of the roof rock beam and the surrounding coal rock, fully absorb the deformation of the roof rock beam and the surrounding rock in the broken area transferred to the airtight wall, and prevent the airtight wall in the goaf from being damaged due to overload.

\section{Material and Methods}

2.1. Material Characterization. The two-component PU grouting material mainly included two parts: a component mainly consisting of polyisocyanates (PAPI, MDI), and B component mainly consisting of polyether polyols (polyether triols, polyether tetraols), catalysts, surfactants, chain extenders, and plasticizers. In this paper, the orthogonal test method was adopted, and the three-factor and four-level orthogonal table (L16) was selected for the test design. The specific experimental scheme is shown in Table 1 , and the raw materials and dosage range used are shown in Table 2. In the grouting experiment part, river sand was selected to test the mechanical properties of grouting materials, and its particle size was $0.25 \mathrm{~mm}-0.5 \mathrm{~mm}$.

2.2. Sample Preparation. Samples preparation mainly included the following two processes.

\subsubsection{Preparation Process of PU Grouting Material}

(a) Component A was prepared by weighing a certain amount of PAPI and MDI, respectively, and mixing the two evenly according to the mass ratio of $4: 1$.

(b) Component $\mathrm{B}$ was prepared by uniformly mixing polyether polyol, catalyst, surfactant, chain extender, and plasticizer according to mass ratio.

\subsubsection{Preparation Process of Grouting Specimens}

(c) The standard cylindrical specimens with a geometric size of $\varphi 50 \times 100 \mathrm{~mm}$ was uniformly selected for the sample mold, and a layer of plastic wrap was laid 
TABLE 1: Orthogonal test scheme of three factors and four levels (L16).

\begin{tabular}{lccc}
\hline Level & Factors & \\
& Polyether polyols $a: b$ & Catalysts A33 & Surfactants BL-8468 \\
\hline 1 & $9: 11$ & 0.5 & 0.5 \\
2 & $10: 10$ & 0.8 & 0.6 \\
3 & $11: 9$ & 1.0 & 0.7 \\
4 & $8: 12$ & 1.2 & 0.8 \\
\hline
\end{tabular}

TABLe 2: Type of raw materials.

\begin{tabular}{lccc}
\hline Raw materials & Type & Dosage range $(\mathrm{g})$ & Specification \\
\hline PAPI & PM-100 & $18.0-25.0$ & Chemically pure \\
MDI (MDI) & PMM-20 & $3.0-6.0$ & Chemically pure \\
Polyether triols & GP-306 & $15.0-25.0$ & Chemically pure \\
Polyether tetraols & HK-4110 G & $15.0-25.0$ & Chemically pure \\
Catalysts & A33 & $0.5-1.2$ & Chemically pure \\
Surfactants & BL-8468 & $0.5-0.8$ & Chemically pure \\
Chain extenders & DEG & 1.2 & Analytically reagent \\
Plasticizers & DOP & 6.0 & Analytically reagent \\
\hline
\end{tabular}

inside the mold to facilitate the mold removal after the sample is formed.

(d) Sand consolidation experiment was carried out according to the slurry-sand ratio of $1: 5$. Sand samples were taken into beakers and fully mixed with the prepared component $\mathrm{A}$.

(e) The mixed sand samples needed to be poured into the mold in 4-6 layers and compacted layer by layer, then component $B$ was injected into the sand sample with a needle tube, and the sand samples were allowed to stand for $30 \mathrm{~min}$. After the PU solution reaction was completed, the samples were taken out and cured for $24 \mathrm{~h}$.

The sample preparation process is shown in Figure 1.

2.3. Viscosity Measurement System. Viscosity is a measure of fluid viscous force and a representation of fluid flow force on its internal friction phenomenon. The viscosity determines the size of the pore size that the slurry can infiltrate and the distance of the diffusion radius. In this experiment, a dynamic rheometer (Anton Paar) was used to measure the viscosity. A coaxial cylinder system was used and the temperature was set at $28^{\circ} \mathrm{C}$, as shown in Figure 2(a). Compared with the traditional viscometer measurement, the shear stress value and viscosity value under different shear rates can be measured by selecting appropriate templates and analysis methods through RheoCompass ${ }^{\mathrm{TM}}$ software, which is more in line with the viscosity change process during grouting.

2.4. Test Setup and AE System. In this paper, the loading system adopted Shimadzu AG-X250 electronic universal testing machine, which was driven by AC motor servo. The loading mode adopted double screw structure. During the test, displacement loading control was adopted until the samples were damaged, and the loading rate was set to
$0.01 \mathrm{~mm} / \mathrm{s}$. At the same time, acoustic emission measurement was carried out in uniaxial compression test, and the acoustic emission monitoring device adopted MISTRAS series PCI-2, as shown in Figure 2(b). In order to avoid the influence of background noise, the gain of the preamplifier was set to $40 \mathrm{db}$ as the input and a threshold value of $40 \mathrm{db}$ is set. Vaseline was used as coupling medium, and the acoustic emission sensor was firmly fixed on the sample with adhesive tape. Before the test, the pencil lead fracture test was carried out to check the sensing ability of the sensor.

\section{Results and Discussion}

\subsection{Characteristics of PU Grouting Materials}

3.1.1. Physical and Chemical Properties. According to the engineering application under different conditions, there are different requirements for the performance of grouting materials. For example, when it is used for waterproofing and plugging in coal mines, it is necessary to pay attention to the hydrolysis resistance of materials. When it is used as filling material for goaf sealing wall, it needs to have certain strength and large deformation characteristics. For most grouting materials, viscosity, gel time, expansion ratio, and compressive strength are the basic indexes to measure their performance. After the material preparation was completed in this experiment, relevant performance indexes were tested, and the test results are shown in Table 3.

From the experimental results, it could be seen that the gel time of the prepared PU grouting material was $57 \mathrm{~s}-73 \mathrm{~s}$, the curing time was $9 \mathrm{~min}-13 \mathrm{~min}$, and a certain strength could be achieved in a short time. The expansion ratio measured by drainage was between 1.3 and 3.5, and the compressive strength varies greatly, with the lowest compressive strength being $1.16 \mathrm{MPa}$ and the highest reaching $12.00 \mathrm{MPa}$. Considering all performance indexes, it could be concluded that, when used as filling material for sealing wall in goaf, the optimal ratio combination of the materials polyether triol: polyether tetraol:catalyst:surfactant:chain 


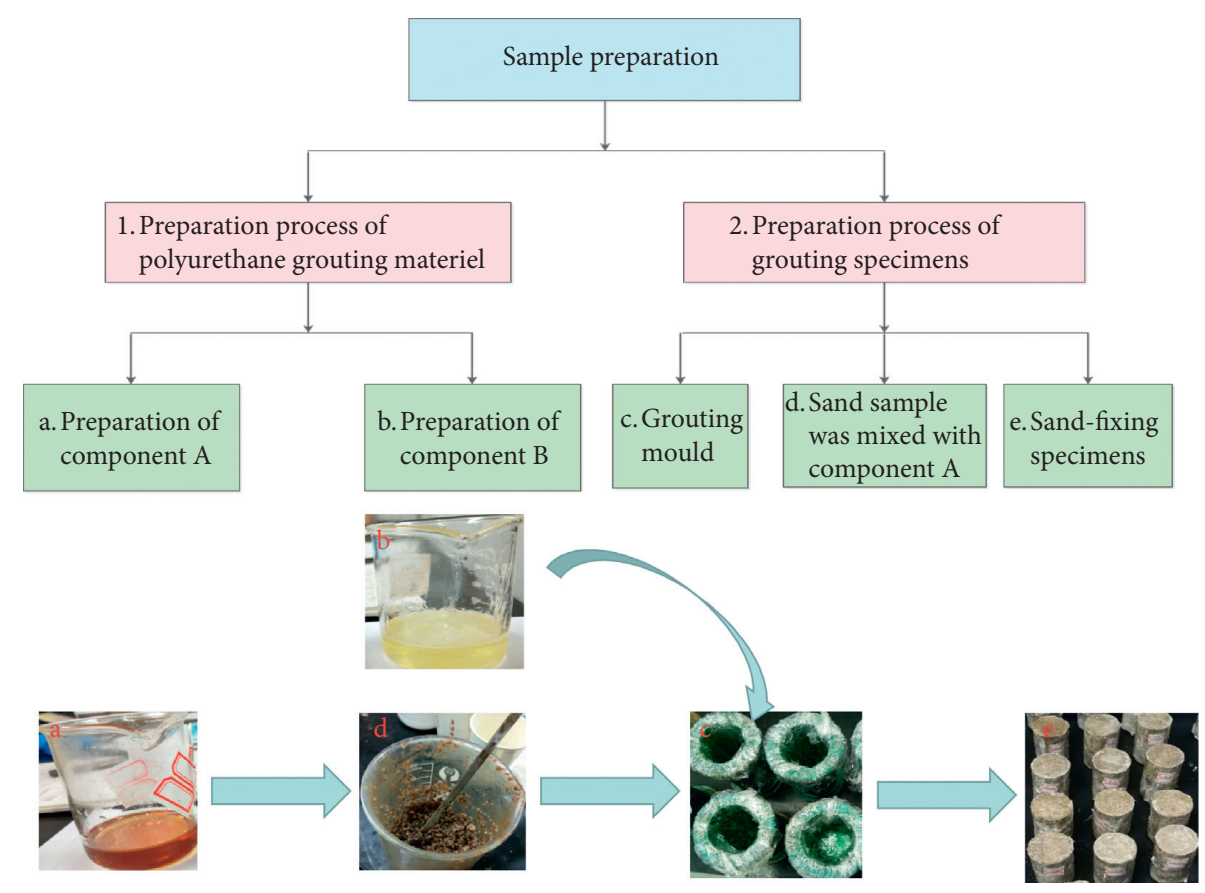

FIgURE 1: Sample preparation process.

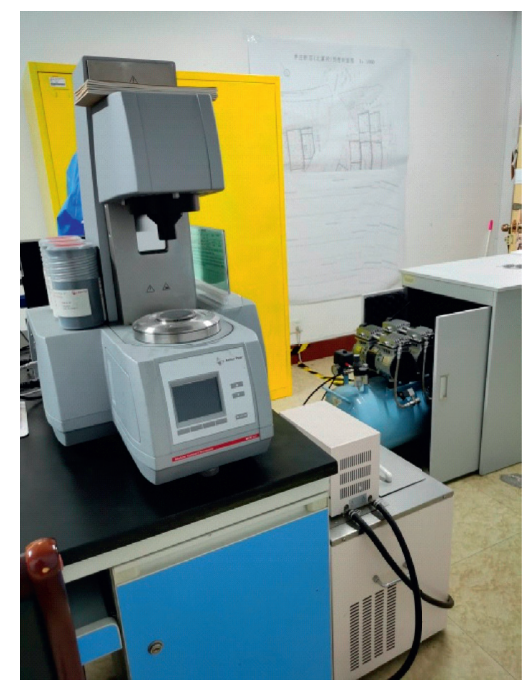

(a)

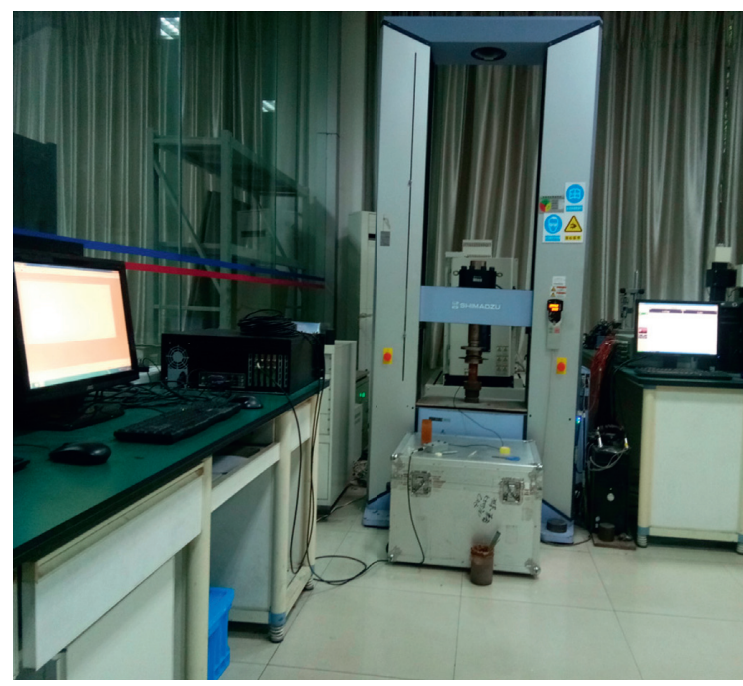

(b)

Figure 2: Experimental equipment. (a) Dynamic rheometer (Anton Paar) and (b) Shimadzu AG-X250 electronic universal testing machine, acoustic emission measurement.

extender:plasticizer was $11: 9: 1.0: 0.5: 1.2: 6.0$. The material prepared by this scheme has high compressive strength and certain deformation and will have good effect in practical engineering application.

3.1.2. Orthogonal Test Analysis of Compressive Strength. Uniaxial compressive strength was an important index to check the failure basis of specimens. This experiment mainly tested the compressive properties of PU grouting materials under different dosage of polyether polyol, catalyst, and surfactant. The average value and range value of each influencing factor under different levels are shown in Figure 3 and Table 4, respectively.

As can be seen from Figure 3, the compressive strength of PU grouting material reached the highest when the ratio of polyether polyols $a: b$ was $11: 9$, which was negatively correlated with the dosage of catalyst and surfactant. The reasons were as follows: on the one hand, when the amount of catalyst added was small, the foaming and gel reactions occurring in the PU preparation process could be well balanced, and the internal structure of the foam was good. 
TABLE 3: Basic performance index of materials.

\begin{tabular}{|c|c|c|c|c|c|}
\hline \multirow{2}{*}{ Serial number } & \multicolumn{5}{|c|}{ Index } \\
\hline & Relative density & Gel time (s) & Curing time $(\min )$ & Expansion ratio & Compressive strength $(\mathrm{MPa})$ \\
\hline 1 & 1.132 & 67 & 11 & 2.9 & 6.48 \\
\hline 2 & 1.119 & 65 & 13 & 3.5 & 3.52 \\
\hline 3 & 1.126 & 61 & 9 & 1.5 & 1.16 \\
\hline 4 & 1.132 & 57 & 11 & 1.3 & 3.65 \\
\hline 5 & 1.137 & 68 & 10 & 2.0 & 7.67 \\
\hline 6 & 1.139 & 63 & 12 & 2.2 & 3.74 \\
\hline 7 & 1.128 & 59 & 10 & 1.3 & 2.29 \\
\hline 8 & 1.130 & 57 & 11 & 1.4 & 2.46 \\
\hline 9 & 1.137 & 73 & 9 & 2.1 & 7.68 \\
\hline 10 & 1.123 & 71 & 13 & 1.9 & 5.17 \\
\hline 11 & 1.143 & 69 & 13 & 2.6 & 12.00 \\
\hline 12 & 1.128 & 64 & 12 & 1.5 & 7.31 \\
\hline 13 & 1.139 & 73 & 11 & 2.1 & 6.77 \\
\hline 14 & 1.143 & 69 & 9 & 2.0 & 8.45 \\
\hline 15 & 1.123 & 66 & 11 & 2.2 & 4.96 \\
\hline 16 & 1.126 & 62 & 10 & 3.3 & 3.07 \\
\hline
\end{tabular}

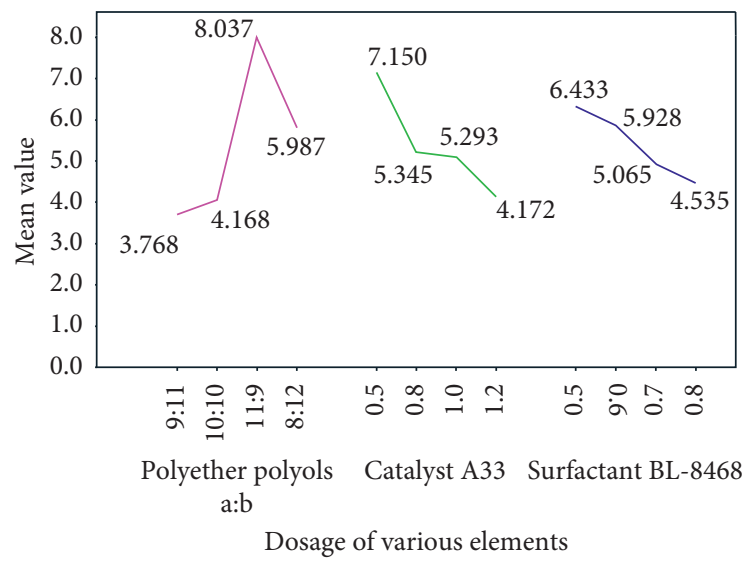

FIgURE 3: Sensitivity analysis between uniaxial compressive strength and various factors.

TABLE 4: Range analysis of compressive strength.

\begin{tabular}{lccc}
\hline Factors & $\begin{array}{c}\text { Polyether polyols } \\
\mathrm{a}: \mathrm{b}\end{array}$ & Catalysts A33 & Surfactants BL-8468 \\
\hline $\mathrm{R}$ & 4.269 & 2.978 & 1.898 \\
\hline
\end{tabular}

With the increase of catalyst content, the foaming reaction rate accelerated, eventually forming collapsed large bubbles, and there were more cracks in the cured samples, which significantly affected the mechanical properties of the material. On the other hand, when the dosage of surfactant was appropriate, the miscibility between the components could be improved, and the collapse of the foam could be effectively prevented, thus obtaining a hard foam with uniform cell distribution and density, and further improving the compressive strength of the hard foam. However, when the amount of foam stabilizer was too large, the bubble film in the system would be too firm and closed-cell foam would be generated, which would reduce the compressive strength of the system and make the material show more brittleness.
Range analysis could judge the sensitivity of each factor. As can be seen from Table 4, the range value of polyether polyol a : $\mathrm{b}$ was the largest, reaching 4.269 , which was much larger than the range value of catalyst and surfactant, and played a major role in controlling the compressive strength of PU grouting materials. The influence of catalyst was second, the range was 2.978 , and the influence of surfactant was the smallest; the range was 1.898 .

According to the analysis of Figure 3 and Table 4, when the ratio of polyether polyol a:b, catalyst and surfactant was $11: 9: 0.5: 0.5$, it was the optimal combination of compressive strength. This group of test was not within the range of orthogonal table, and this scheme could be applied when optimizing the material ratio.

\subsection{Grouting Sand Consolidation Test}

3.2.1. Failure Process. At the beginning of the test, there was no significant change in the sand-fixing specimens. Elastic strain was generated in the specimens first, and no microcracks were generated in the specimens at this time. With the increase of force, vertical cracks began to appear on the surface of the specimens perpendicular to the loading surface, and the crack propagation was relatively stable. After that, with the continuation of loading, the cracks rapidly expanded and propagated to the loading surface. Finally, the specimens broke due to the formation and propagation of cracks. From the macroscopic fracture behavior, it can be seen that the solid sand sample was brittle fracture mode. The failure of some specimens is shown in Figure 4.

3.2.2. Viscosity Test Results. In this experiment, the viscosity of component A was relatively low and had good fluidity and groutability, so only the viscosity of component $\mathrm{B}$ needed to be considered. The dosage of polyether tetraol directly determined the viscosity of component $B$, because the viscosity of polyether tetraol was relatively high, reaching $2000 \mathrm{mpa} \cdot \mathrm{s}$. Therefore, when the viscosity test was carried out, 16 groups of tests were 

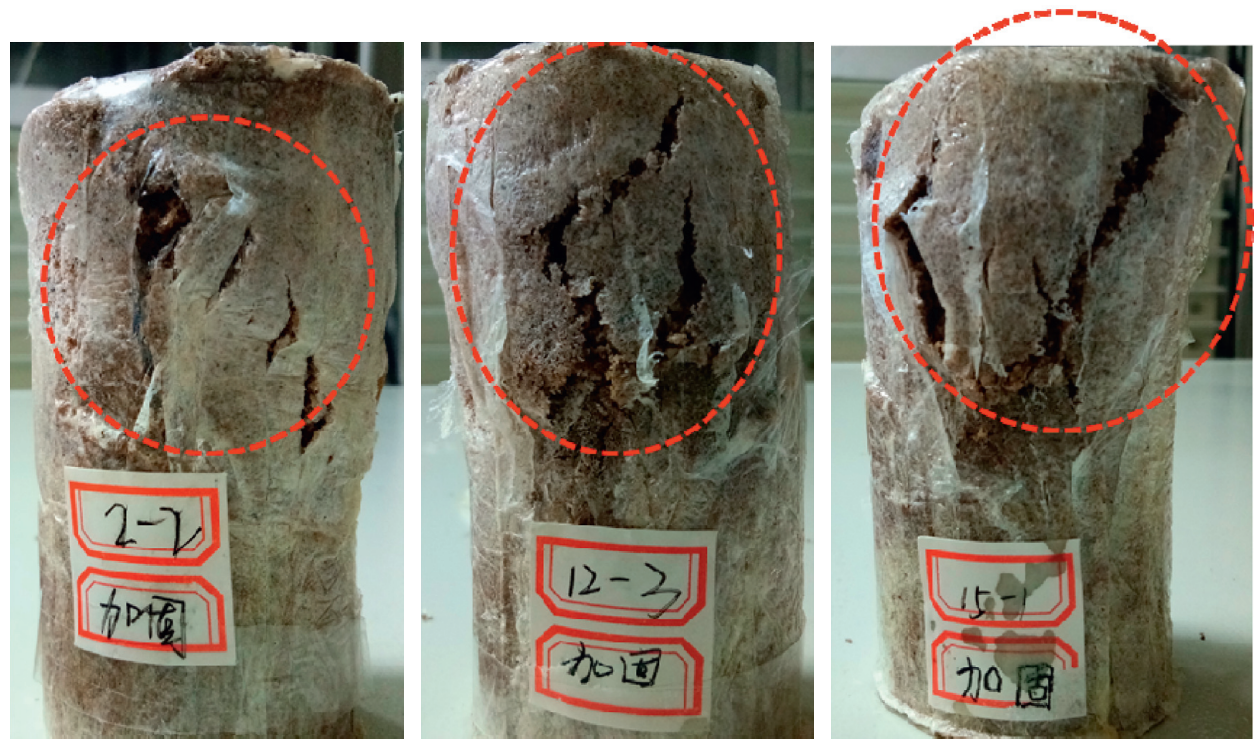

FIgURE 4: Splitting failure of specimens under uniaxial compression.

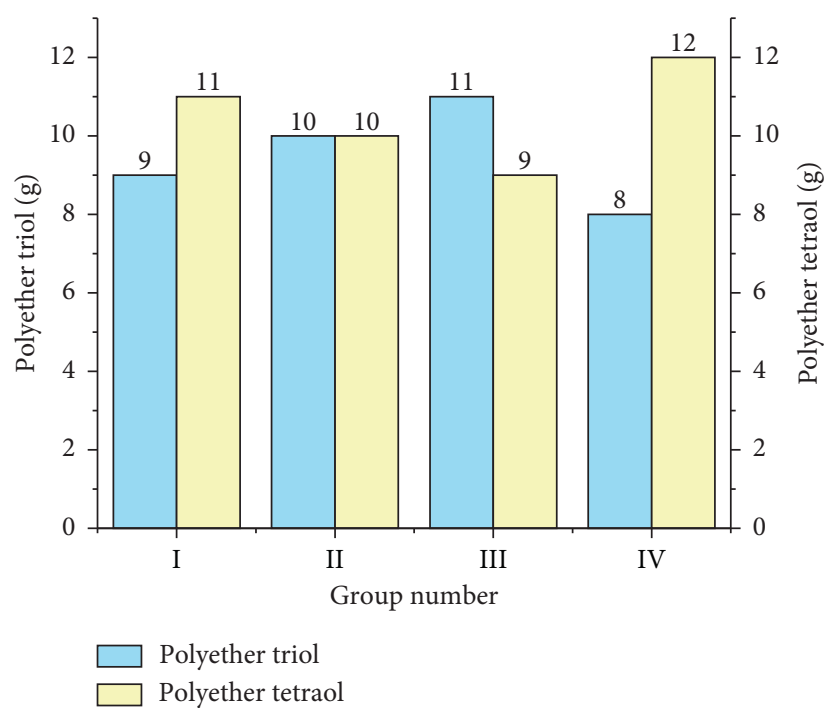

Figure 5: Dosage of polyether triol and polyether tetraol.

divided into 4 groups according to the dosage of polyether tetraol. The amounts of polyether triols (GP-306) and polyether tetraols (HK-4110G) in each group are shown in Figure 5.

Most polymers and their plastics melt and concentrated solution belong to pseudoplastic fluid. Pseudoplastic fluid is the most common non-Newtonian fluid. The flow curve of this fluid is nonlinear. The increase of shear rate is faster than that of shear stress, and there is no yield stress. It is characterized in that its viscosity decreases with the increase of shear rate or shear stress, which is called shear thinning fluid. This shear thinning phenomenon is caused by the reduction of flow resistance caused by the orientation, extension, deformation, or dispersion of particles in the fluid. The shear thinning phenomenon is reversible and can return to the original viscosity when the shear rate decreases or disappears $[35,36]$.
To describe the rheological behavior of pseudoplastic non-Newtonian fluid, Carreau model can be selected for mathematical fitting of flow curves.

$$
\eta^{*}=\eta\left[1+\left(\frac{\eta \dot{\gamma}}{G}\right)^{2}\right]^{(n-1) / 2}
$$

where $\lambda$ is the characteristic time of materials, $\mathrm{G}$ is shear modulus $(\mathrm{Pa})$, and $\mathrm{n}$ is power exponent.

This equation can completely describe the whole process of viscosity change with shear rate. At a higher shear rate, $\lambda \dot{\gamma}>1$, this equation reflects the characteristics of pseudoplastic flow with shear thinning of apparent density. 

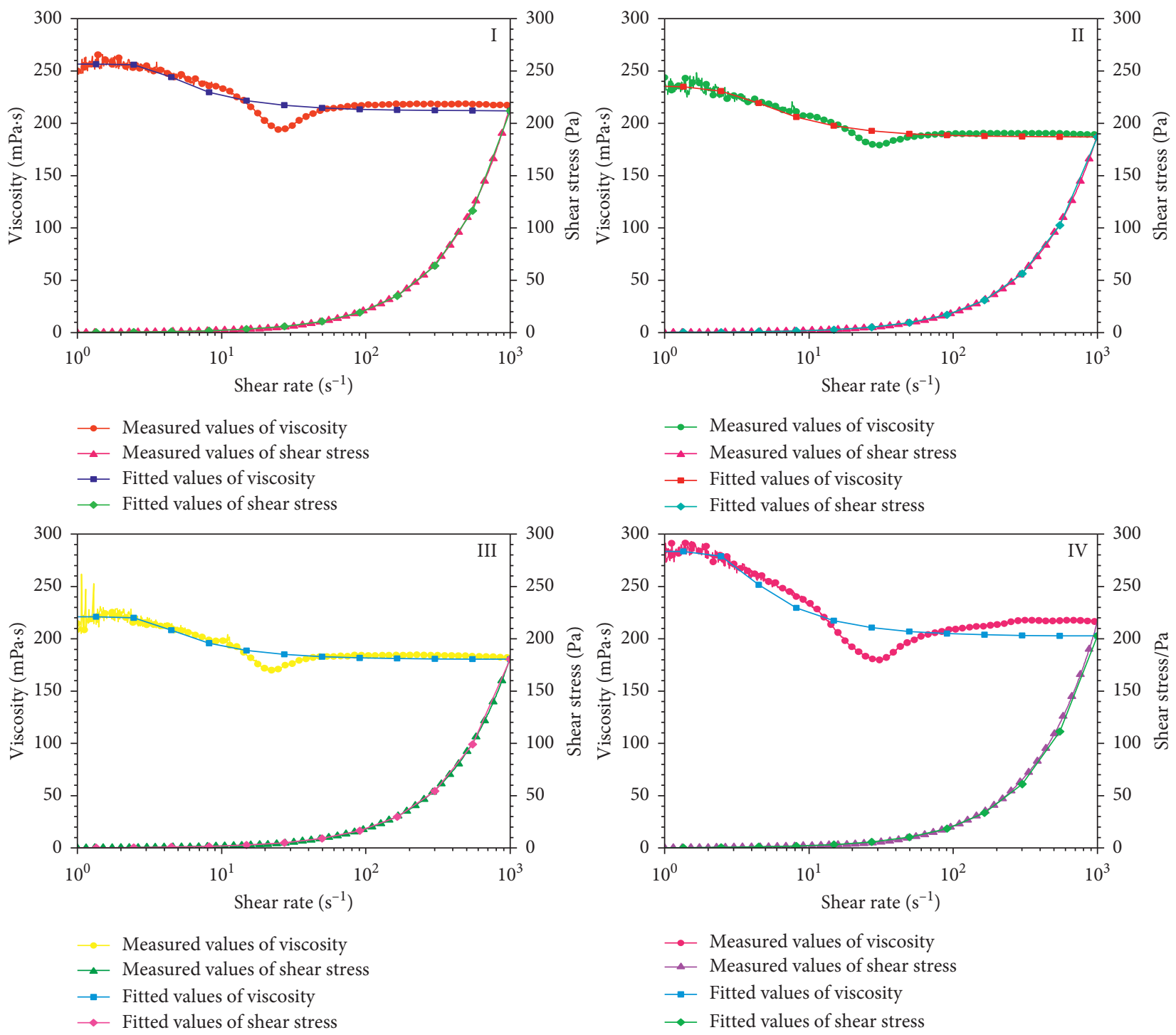

Figure 6: Viscosity measurement curve and fitting curve.

TABLE 5: Viscosity value of component B.

\begin{tabular}{lc}
\hline Group of specimens & Viscosity (MPa·s) \\
\hline Group I & 258 \\
Group II & 235 \\
Group III & 220 \\
Group IV & 284 \\
\hline
\end{tabular}

In this paper, dynamic rheometer was used to measure the shear rate, shear stress, viscosity, and other parameters of grouting material, and Carreau model was used to carry out linear fitting of flow curve, as shown in Figure 6. With the increase of shear rate, the viscosity decreased continuously, which conformed to the characteristics of pseudoplastic fluid. The viscosity measurement results are shown in Table 5. From the experimental results, it could be seen that with the increase of polyether tetraol dosage the viscosity of grouting materials increased continuously, which verified the reliability of grouping basis.
3.2.3. Analysis of Viscosity and Compressive Strength. In order to ensure the accuracy of the test, three sand-containing specimens were made for each test scheme, their compressive strength was measured, and the average compressive strength was calculated. The results were shown in Table 6. As can be seen from Table 5, that comparison result of viscosity was IV $>$ I $>$ II $>$ III. As can be seen from Table 6 , that result of average compressive strength was II $>$ IV $>$ II $>$ I. According to the analysis of viscosity and compressive strength, the average compressive strength of group III was the largest, and the viscosity of group III was the smallest, while low viscosity meant excellent fluidity and diffusion. Under the same grouting amount and grouting pressure, the viscosity of group III was small, which could diffuse more efficiently and had a larger diffusion radius. In a short period of time, the larger the diffusion radius, the more complete the contact between component $\mathrm{A}$ and component $B$, and the more sufficient the reaction would be, so the obtained samples had higher compressive strength. The 
TABLE 6: Average compressive strength of sand-containing samples.

\begin{tabular}{lcl}
\hline Group of specimens & Number of specimens & Average compressive strength (MPa) \\
\hline \multirow{3}{*}{ Group I } & 1 & 1.25 \\
& 2 & 0.97 \\
& 3 & 0.89 \\
& 4 & 1.25 \\
Group II & 5 & 0.79 \\
& 6 & 1.08 \\
\hline & 7 & 0.88 \\
Group III & 8 & 0.66 \\
& 9 & 0.96 \\
& 10 & 1.31 \\
Group IV & 11 & 1.37 \\
& 12 & 0.88 \\
\hline
\end{tabular}

average compressive strength of the pure slurry specimens of group IV was higher than that of groups I and II. This was due to the large amount of polyether tetraol in group IV; the higher the functionality and hydroxyl value of polyether polyol, and the higher the density of cross-linked network formed by reaction with isocyanate. With the increase of molecular mass, the compressive strength increased. However, in the sand-containing specimens, the average compressive strength of group IV was the smallest, which was related to viscosity. The viscosity of group IV was large, which led to slow diffusion of slurry and insufficient reaction, and there were many stress weaknesses in the specimens.

However, in group III, when the ratio of polyether triol: polyether tetraol:catalyst:surfactant:chain extender:plasticizer was $11: 9: 1.0: 0.5: 1.2: 6.0$, the maximum compressive strength was $1.13 \mathrm{MPa}$. Therefore, it had excellent performance when used as filling material for sealing wall in goaf.

3.2.4. Principle of Acoustic Emission Detection. The acoustic emission (AE) phenomenon has been used as a powerful tool with the purpose to either detect, locate, or assess damage for a wide range of applications [37]. Deformation and crack propagation of materials under stress are important mechanisms of structural failure. This source, which is directly related to deformation and fracture mechanism, is called acoustic emission source. Elastic waves emitted from acoustic emission sources eventually propagate to the surface of the material, causing surface displacement that can be detected by acoustic emission sensors. These detectors convert mechanical vibrations of the material into electrical signals, which are then amplified, processed, and recorded. The principle of acoustic emission detection is shown in Figure 7.

3.2.5. Analysis of Acoustic Emission Energy and Compressive Strength. In this study, the energy of a single event collected from acoustic emission signals was analyzed as acoustic emission parameters. During the experiment, macroscopic failure initiation, corresponding stress fluctuation, and energy change curves of each group of samples were observed. Parameter energy was defined as the sum of the energies of various frequency components in the analyzed frequency range. The change process of stress and energy during loading is shown in Figure 8, and the energy value of most specimens was in the range of $0-400$.

As shown in Figure 8, acoustic emission phenomenon was divided into three stages:

(i) Nondamage phase: only scattered low-level acoustic emission events.

(ii) Initial stage of damage: acoustic emission events increased, but energy accumulation was slow. The main reason for damage was the cracking of the matrix under low stress.

(iii) The following stages of damage: the main crack appeared, the energy accumulation speed accelerated, and a larger peak signal appeared.

AE events cluster phenomenon was obvious at the fracture and instability of the specimens, and AE events occurred in other parts, but they were distributed in a loose way. This could be explained as acoustic emission was an energy release phenomenon. When the energy concentration caused by stress/strain reached the fracture toughness of the material, the crack propagated and elastic waves reappeared. In group I, four obvious energy signal peaks were generated during the test, which was due to stress concentration during the loading process of the specimens. At the beginning of loading, the crack initiated and propagated, so the released energy was small. The crack was near the peak strength, and a large amount of energy accumulated during loading, resulting in a large released energy during cracking. When the specimens were unstable, the peak value of $\mathrm{AE}$ signal reached the maximum and the strength of the specimens decreased rapidly. Due to different material configurations and crack propagation modes, AE signal peaks were also quite different, with peaks of 74 and 380 , 


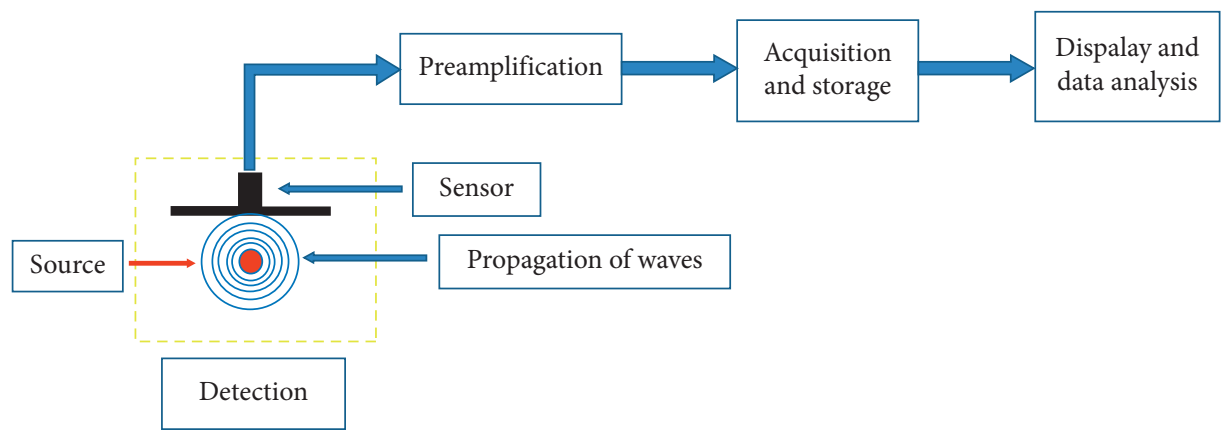

FIGURE 7: Schematic diagram of acoustic emission detection.
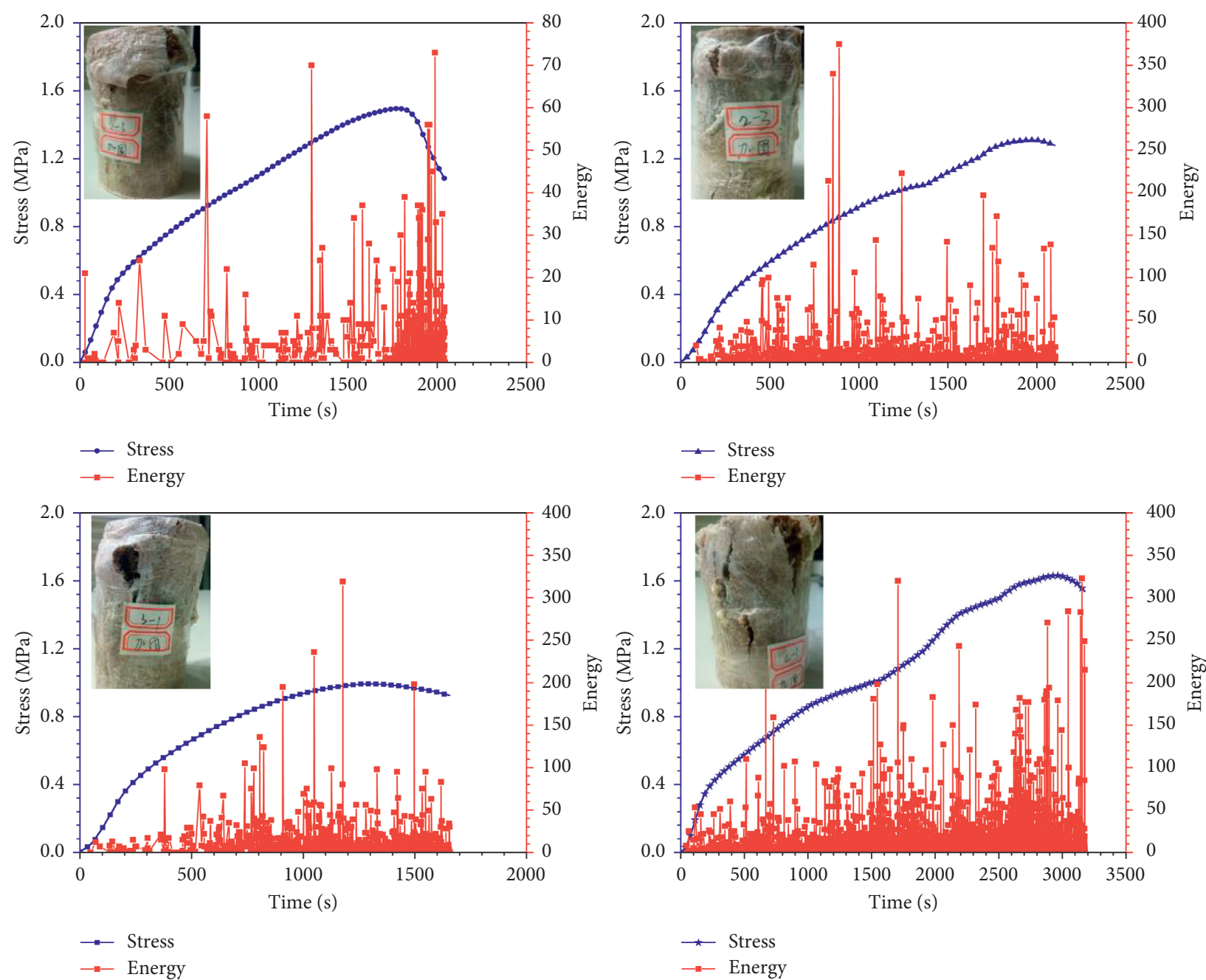

(a)

Figure 8: Continued. 

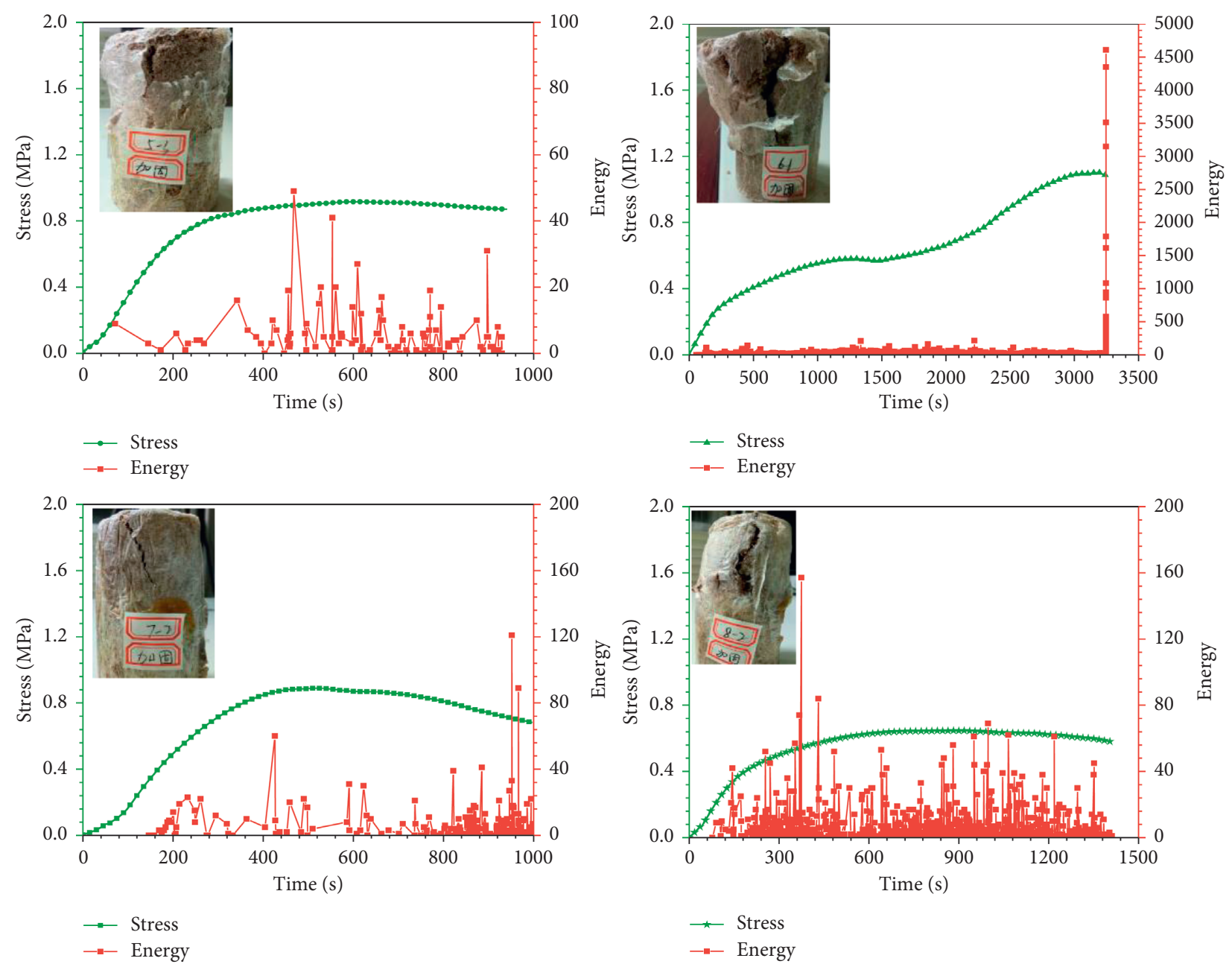

(b)

Figure 8: Continued. 

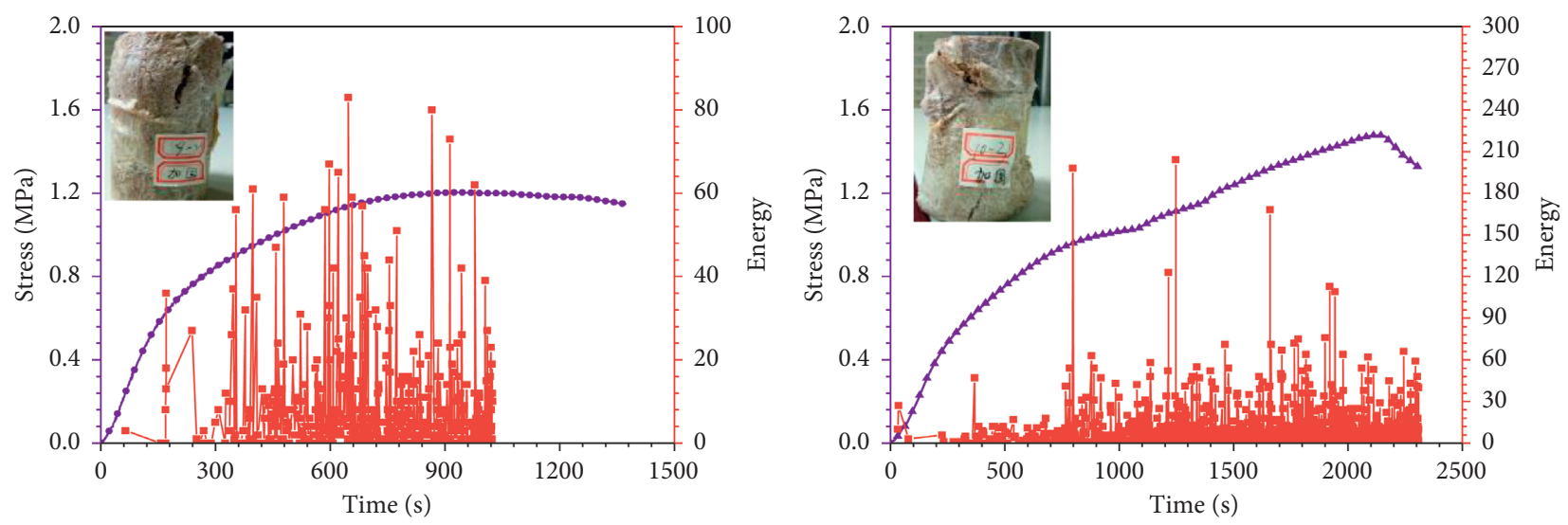

$$
\begin{aligned}
& \longrightarrow \text { Stress } \\
& -- \text { Energy }
\end{aligned}
$$$$
\text { ^ Stress }
$$
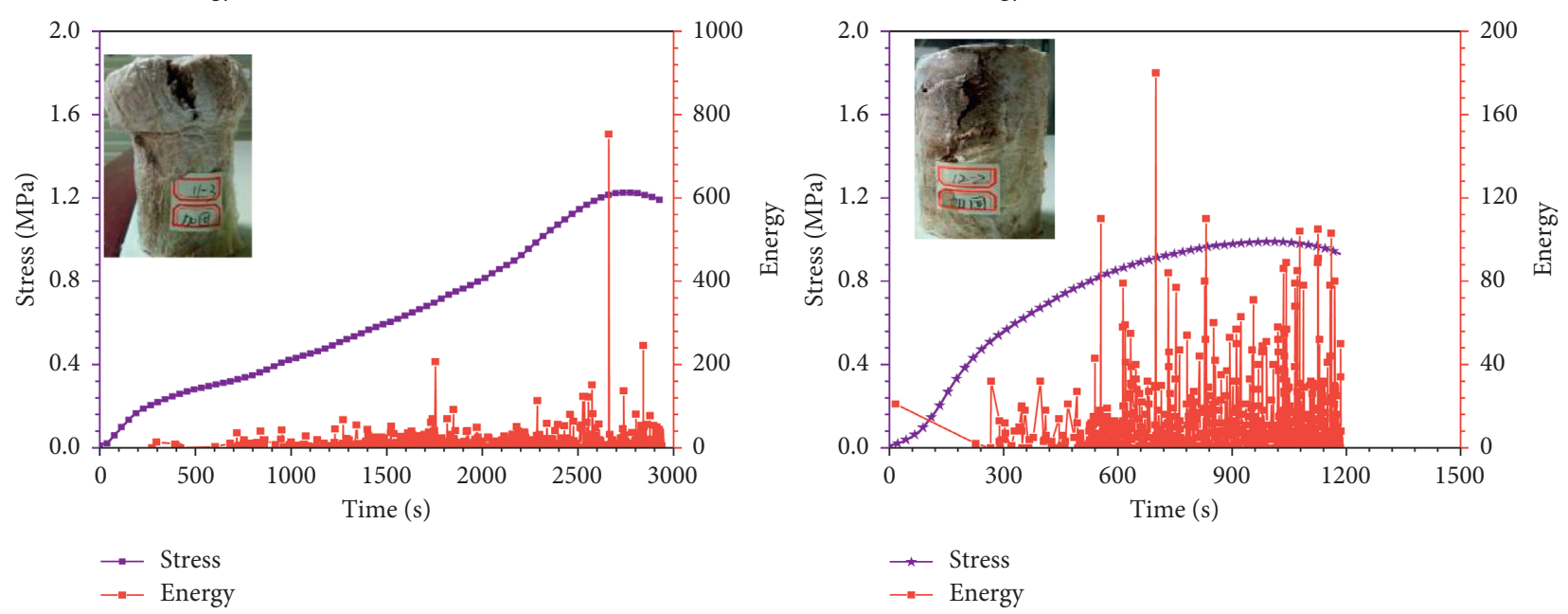

$\rightarrow$ Stress

- - Energy

(c)

Figure 8: Continued. 

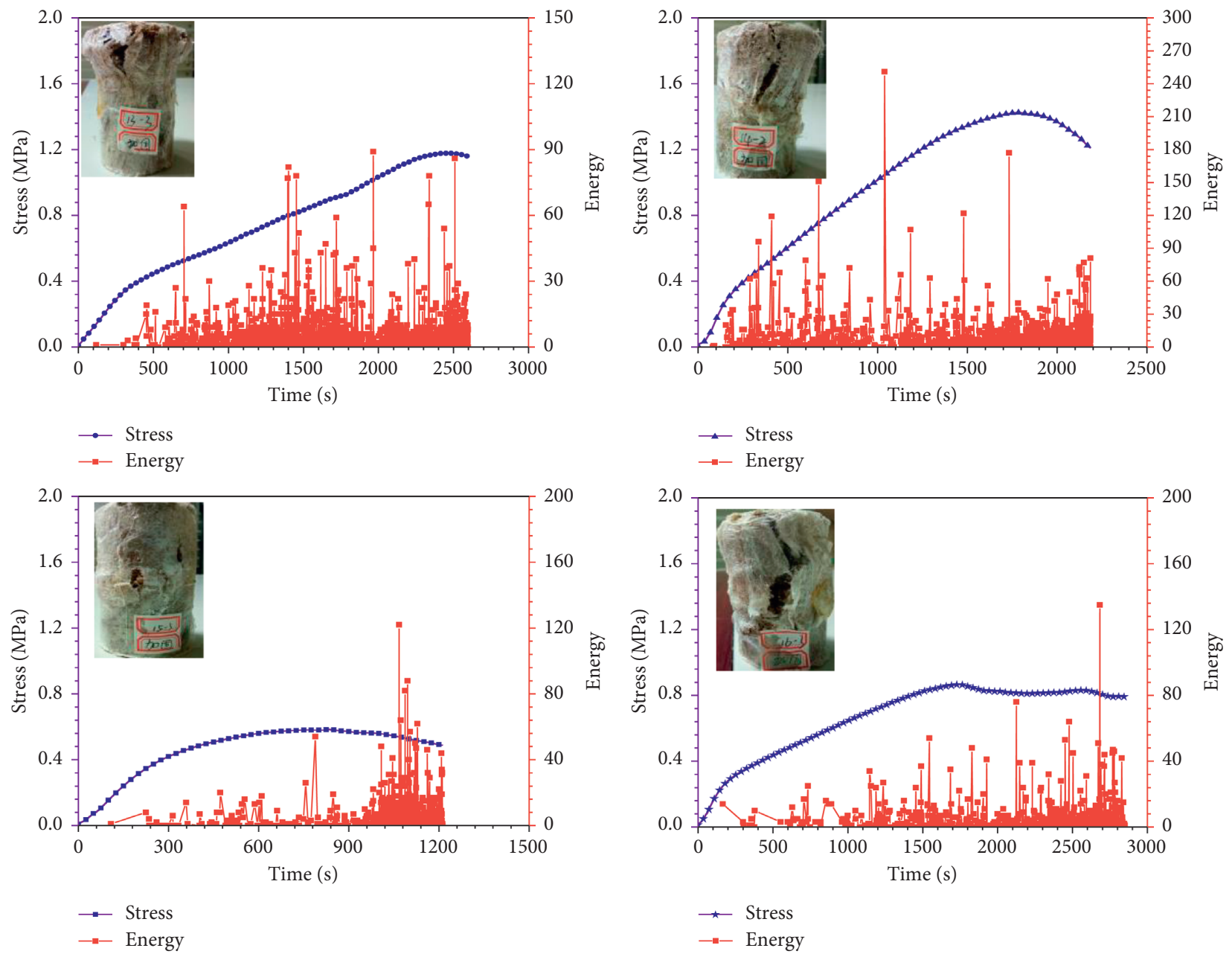

(d)

Figure 8: Analysis chart of acoustic emission results.

respectively. In group $\mathrm{II}$, the compressive strength and $\mathrm{AE}$ signal peak value of the specimens were generally small, and a deviation value appeared in the process of acoustic emission signal collection, which was due to the splitting failure of the specimens and the generation of large cracks. In group III, AE events were concentrated, which was due to the appearance of more small cracks in the specimens. In group IV, weak AE signals were mainly generated by friction between sand particles during loading. When large cracks were generated, AE signals were strengthened.

\section{Conclusion}

Aiming at the problem of crack or fracture in goaf under mining stress, PU filling material with certain strength was prepared in this study, and its basic properties such as viscosity, foaming ratio, and compressive strength were measured. The generation and propagation of crack were monitored by acoustic emission equipment, and the following conclusions were obtained:
(1) The gel time, curing time, expansion ratio, and other properties of the prepared polyurethane grouting material can be adjusted according to specific needs. In this study, when the ratio of polyether triol:polyether tetraol:catalyst:surfactant:chain extender: plasticizer is $11: 9: 0.5: 1.0: 1.2: 6.0$, the PU grouting material has higher injectability and ideal compressive strength, which is the optimal combination of this experiment.

(2) According to the viscosity analysis, in the four groups of experiments with different polyether polyol content, when the ratio of polyether triol to polyether tetraol was $8: 12$, the viscosity can reach $284 \mathrm{MPa} s$ at the highest, and when the ratio of polyether triol to polyether tetraol was $11: 9$, the minimum was $220 \mathrm{MPa} s$, which belonged to a low viscosity fluid and had good injectability.

(3) The compressive strength of pure slurry specimens was in the range of $1.16-12.0 \mathrm{MPa}$, and the orthogonal test results showed that the dosage of 
polyether polyol had the greatest influence on the compressive strength, and the compressive strength reached the maximum when the ratio of polyether polyol to polyether tetraol was 11:9; The average compressive strength of sand-containing specimens was in the range of $0.82-1.13 \mathrm{MPa}$, and the average compressive strength of group III was the highest, which was consistent with the compressive strength of pure slurry specimens.

(4) Acoustic emission technology was used to monitor the whole process of sand-containing specimens from initial crack generation to final failure. The energy value of acoustic emission signal was in the range of $0-400$. When cracks were generated and propagated, AE events increased and the energy value increased.

\section{Data Availability}

The experimental data used to support the findings of this study are available from the corresponding author upon request.

\section{Conflicts of Interest}

The authors declare that there are no conflicts of interest regarding the publication of this paper.

\section{Acknowledgments}

This research was funded by the China National Natural Science Foundation (nos. 41807211, 51904032, and 51874192), Open Fund of Mine Disaster Prevention and Control Key Laboratory of Ministry of Education (no. MDPC201920), and SDUST Research Fund (Grant no. 2018TDJH102).

\section{References}

[1] Y. Tai, H. Xia, X. Meng, and T. Kuang, "Failure mechanism of the large-section roadway under mined zones in the ultrathick coal seam and its control technology," Energy Science \& Engineering, vol. 8, no. 4, pp. 999-1014, 2020.

[2] W. Wang, "Discussion on the current application situation and development countermeasures of polymer grouting materials used in coal mine," Guang dong Chemical Industry, vol. 47, no. 7, pp. 127-128, 2020.

[3] Y. L. Chen and Y. C. Li, "Mechanical properties and consolidation performances of high-polymer material in coal," Energies, vol. 13, no. 1, 2020.

[4] Z. C. Zhang, K. Liu, and Z. L. Zhan, "Application of polymer grouting reinforcement technology in the treatment of slope collapse," AER-Advances in Engineering Research, vol. 84, pp. 244-249, 2016.

[5] J. Liu, Y. Li, G. Zhang et al., "Effects of cementitious grout components on rheological properties," Construction and Building Materials, vol. 2019, no. 227, pp. 1-13, 2019.

[6] D. K. Chattopadhyay and K. V. S. N. Raju, "Structural engineering of polyurethane coatings for high performance applications," Progress in Polymer Science, vol. 32, no. 3, pp. 352-418, 2007.
[7] H. Liang, L. Fan, and Y. Z. Li, "Study on influencing factors of strength of polyether polyurethane grouting materials," Journal of Wuhan University of Technology, vol. 44, pp. 172176, 2020.

[8] B. George, L. Pierson, and R. Barrows, "Research in using Polyurethane Foam to Mitigate Rock Bolt Installation Difficulties," Transportation Research Record: Journal of the Transportation Research Board, vol. 2672, no. 52, pp. 307-315, 2018.

[9] M. R. Islam, M. D. H. Beg, and S. S. Jamari, "Development of vegetable-oil-based polymers," Journal of Applied Polymer Science, vol. 131, no. 18, pp. 1-13, 2014.

[10] J. O. Akindoyo, M. D. H. Beg, S. Ghazali, M. R. Islam, N. Jeyaratnam, and A. R. Yuvaraj, "Polyurethane types, synthesis and applications - a review," RSC Advances, vol. 6, no. 115, pp. 114453-114482, 2016.

[11] G. T. Howard, "Polyurethane biodegradation," in Environmental Science and Engineering Applied and Environmental Microbiology, pp. 371-394, Springer-Verlag, Berlin, Germany, 2012.

[12] S. Saleh, N. Z. M. Yunus, K. Ahmad, and N. Ali, "Improving the strength of weak soil using polyurethane grouts: A review," Construction and Building Materials, vol. 202, pp. 738-752, 2019.

[13] C. W. Patterson, D. Hanson, A. Redondo et al., "Conformational analysis of the crystal structure for MDI/BDO Hard segments of polyurethane elastomers," Journal of Polymer ence Part B Polymer Physics, vol. 37, no. 17, pp. 2303-2313, 2015.

[14] J. H. Guo, Y. C. Liu, T. Chai et al., "Synthesis and properties of a nano-silica modified environmentally friendly polyurethane adhesive," RSC Advances, vol. 5, no. 56, pp. 44990-44997, 2015.

[15] V. Mittal, J. K. Kim, K. Pal et al., "Recent advances in elastomeric nanocomposites," Advanced Structured Materials, vol. 9, 2011.

[16] N. Roohpour, J. M. Wasikiewicz, A. Moshaverinia, D. Paul, M. F. Grahn, and I. U. Rehman, "Polyurethane membranes modified with isopropyl myristate as a potential candidate for encapsulating electronic implants: a study of biocompatibility and water permeability," Polymers, vol. 2, no. 3, pp. 102-119, 2010.

[17] USA-EPA, Assessment, Dfe Alternatives Polyurethane, Flexible Flame, Foam Classification, Flame Retardant Sources, Data Properties, Chemical Transport, Environmental Toxicity, Evaluating Environmental, vol. EPA 744-R-, no. 002, 2015.

[18] M. A. Mekewi, A. M. Ramadan, F. M. Eldarse et al., "Preparation and characterization of polyurethane plasticizer for flexible packaging applications: natural oils affirmed access," Egyptian Journal of Petroleum, vol. 26, no. 1, pp. 9-15, 2016.

[19] Z. Yang, X. Zhang, X. Liu, X. Guan, C. Zhang, and Y. Niu, "Flexible and stretchable polyurethane/waterglass grouting material," Construction and Building Materials, vol. 138, pp. 240-246, 2017.

[20] Z. He, Q. Li, J. Wang, N. Yin, S. Jiang, and M. Kang, "Effect of silane treatment on the mechanical properties of polyurethane/water glass grouting materials," Construction and Building Materials, vol. 116, pp. 110-120, 2016.

[21] X. Liu, J. Wang, K. Huang et al., "Experimental Study on Dynamic Water Grouting of Modified Water-Soluble Polyurethane," KSCE Journal of Civil Engineering, vol. 23, no. 8, pp. 3897-3906, 2019.

[22] X. Hong, W. Dong, S. Yang, B. Mu, and B. Liang, "Study on structure and performance of reactive silicate reinforced 
polyurethane composite," Polymer Engineering \& Science, vol. 55, no. 10, pp. 2322-2327, 2015.

[23] C. R. Qin, W. Lu, and Z. L. He, "Effect of Silane Treatment on Mechanical Properties of Polyurethane/Mesoscopic Fly Ash Composites," Polymers, vol. 11, no. 4, p. 741, 2019.

[24] C. Zhang, B. Shuai, X. Zhang, X. Hu, H. Zhang, and Y. Jia, "Polyurethane/Red Mud Composites with Flexibility, Stretchability, and Flame Retardancy for Grouting," Polymers, vol. 10, no. 8, p. 906, 2018.

[25] Z. H. Zhang, K. Liu, and L. Z. Ye, Application of polymer grouting reinforcement technology in the treatment of slope collapse, pp. 244-249, Atlantis Press, Beijing, China, 2016.

[26] A. Mortazavi and A. Maadikhah, "An investigation of the effects of important grouting and rock parameters on the grouting process," Geomechanics and Geoengineering, vol. 11, no. 3, pp. 219-235, 2016.

[27] K. Liu, W. Liang, F. Ren, J. Ren, F. Wang, and H. Ding, "The study on compressive mechanical properties of rigid polyurethane grout materials with different densities," Construction and Building Materials, vol. 206, pp. 270-278, 2019.

[28] C. Toraldo, G. Modoni, M. Ochmański, and P. Croce, "The characteristic strength of jet-grouted material," Géotechnique, vol. 68 , no. 3, pp. 262-279, 2018.

[29] M. G. Li, M. R. Du, F. M. Wang et al., "Study on the mechanical properties of polyurethane (PU) grouting material of different geometric sizes under uniaxial compression," Construction and Building Materials, vol. 259, 2020.

[30] J. X. Zhang, X. G. Pei, T. Ni et al., "Study on a novel chemical slurry and the mechanical behavior of cemented sand," Journal of Adhesion Science and Technology, vol. 34, pp. 1-18, 2020.

[31] J.-W. Lee, H. Kim, and T.-M. Oh, "Acoustic Emission Characteristics during Uniaxial Compressive Loading for Concrete Specimens according to Sand Content Ratio," KSCE Journal of Civil Engineering, vol. 24, no. 9, pp. 2808-2823, 2020.

[32] J.-S. Kim, Y.-C. Choi, G.-C. Cho et al., "A combined method of Wigner-Ville distribution with a theoretical model for acoustic emission source location in a dispersive media," KSCE Journal of Civil Engineering, vol. 17, no. 6, pp. 12841292, 2013.

[33] J. J. Men, J. C. Wang, L. Y. Gou et al., "Acoustic emission behavior and damage evaluation of recycled aggregate concrete under compression," Structural Control and Health Monitoring, vol. 27, 2020.

[34] C. Guo, B. Sun, D. Hu, F. Wang, M. Shi, and X. Li, "A Field Experimental Study on the Diffusion Behavior of Expanding Polymer Grouting Material in Soil," Soil Mechanics and Foundation Engineering, vol. 56, no. 3, pp. 171-177, 2019.

[35] J D. Niu, B. Wang, C. Feng et al., "Experimental research on viscosity characteristics of grouting slurry in a high ground temperature environment," Materials, vol. 13, no. 14, 2020.

[36] R. Xia, B. Li, Y. Z. Tang et al., "Study on storage stability and groutability of two-component grouting materials using dynamic rheological approach," Transactions on Materials Science and Engineering, vol. 124, 2017.

[37] F. Piñal-Moctezuma, M. Delgado-Prieto, and L. RomeralMartínez, "An acoustic emission activity detection method based on short-term waveform features: Application to metallic components under uniaxial tensile test," Mechanical Systems and Signal Processing, vol. 142, 2020. 